\title{
An evolutionary approach to project management process improvement for software-intensive projects
}

\author{
Paweł Pierzchałka \\ Q-Labs GmbH, Germany \\ Ingersheimer Str. 20, 70499 Stuttgart \\ pawel.pierzchalka@q-labs.de,ppierzchalka@yahoo.de
}

\begin{abstract}
Project management plays an important role in software engineering discipline. Project management is about delivering projects "on time", "in budget" and "in quality". Introducing, applying and improving project management process requires systematical and coordinated approach, which helps to overcome organizational barriers, reduce implementation cost, provide knowledge sharing and secure achieved results. Many companies within the software-intensive automotive industry have decided to start the organizationwide process improvement programs. In this context, project management is one of the first key issues on the way to the better processes. This article presents an evolutionary approach to introducing and improving project management organizational methodology. It defines steps needed for incremental implementation of project management in software-intensive organization and its component-projects. It discusses the key success factors, prerequisites, methods and tools used on the way to the better, systematical, universal and practicable project management process.
\end{abstract}

\section{Introduction}

Nowadays project management is an increasingly growing discipline. Many international and local organizations (such as Project Management Institute in U.S., Gesellschaft für Projekt Management in Germany, or Polskie Towarzystwo Informatyczne, Sekcja Zarzadzania Projektami in Poland) are supporting the growth and improvement of project management. These organizations promote the usage of the modern project management principles across all disciplines, with a special focus on software industry. They also support practitioners in mastering their project work.

The modern process and quality reference models underline the role of project management in the development work. Such models as CMMI, ISO15504, or PMBOK provide an extensive guidance on project management [1-5].

Project management is now recognized as one of the basic methods in the modern software engineering. It is one of the essential elements enabling the success of the software and system development initiatives [6-8].

The automotive industry has also recognized the importance of project management in the electronic and software-intensive development projects. In the next dec-

Please use the following format when citing this chapter:

Pierzchalka, P., 2006, in IFIP International Federation for Information Processing, Volume 227, Software Engineering

Techniques: Design for Quality, ed. K. Sacha, (Boston: Springer), pp. 127-138. 
ade electronic and software will account for approximately $90 \%$ of all future automotive innovation. Electronic and software are becoming critically important and will share approximately $40 \%$ of the cost of car production. At the same time the complexity of the software-intensive systems in modern vehicles is rapidly growing. Nowadays a high number of electronic control units are present in the car. They communicate through internal buses and influence each other. Almost every part of the car is now controlled by electronic and software - starting with engine/gear control, chassis, traction control systems, windows, light control and ending with the modern car navigation and entertainment systems.

The increasing role of software in modern vehicles requires better management of the car development projects. In order to deal with the size and complexity of the vehicle systems, automotive companies have decided to start the company-wide process improvement programs. By introducing process improvement they want to deal better with the increasing complexity, improve product quality, to improve productivity and efficiency of the development departments. Within those process-oriented approaches, project management process plays an important role, already at the beginning of a process improvement initiative.

The experience gained during the implementation of project management in the context of software-intensive automotive systems lead to this work. This article presents an evolutionary approach to introducing and implementing the project management methodology within software-intensive automotive systems. It presents the key factors, methods and selected tools, which lead to the successful and sustaining implementation of the project management within the organization. The special focus is put on the component-projects - projects that aim to develop the single softwareintensive component (e.g.: electronic gear control, control panel, roof control panel) resulting from the cooperation between the OEM and suppliers.

\section{An Evolutionary Approach to Project Management Process Improvement}

The article presents an evolutionary approach to introducing and improving the project management within the context of the organizational process improvement program. It is based on the author's experience collected during the implementation of the project management principles within multiple automotive companies. It presents the suggestion of the Project Management Process Improvement Model (PM-PIM). The article introduces the maturity levels needed for introducing, carefully implementing and then mastering project management within the software-intensive organization. The proposed levels build on each other, e.g.: establishing the project management framework (Level 1) is a prerequisite for starting with piloting and rollout of project management practices in the component development projects (Level 2). Implemented project management practices (Level 2) are the basis for more advanced project management, including definition of the tailoring guidelines for project management process, quantitative project management and further continuous improvement (Level 3). 

projects

The content of the suggested Project Management Process Improvement Model (PM-PIM) is presented on the Figure 1.

\begin{tabular}{|c|c|}
\hline \multicolumn{2}{|r|}{ Project Management Process Improvement Model (PM-PIM) } \\
\hline $\begin{array}{l}\text { Level } 3 \text { (Organization) } \\
\text { Making improved project } \\
\text { management processes } \\
\text { "state of the art" in the } \\
\text { organization and mastering } \\
\text { project management }\end{array}$ & $\begin{array}{l}\text { Sustaining } \\
\text { - Continuously improving project management } \\
\text { - Tailoring the organizational process } \\
\text { - Collecting Lessons Learned } \\
\text { - Filling PM Knowledge Repository } \\
\text { - Quantitatively managing projects } \\
\text { - Using measurement data }\end{array}$ \\
\hline $\begin{array}{l}\text { Level } 2 \text { (Project) } \\
\text { Introducing basic, and then } \\
\text { more advanced project } \\
\text { management practices - } \\
\text { focus on a project }\end{array}$ & $\begin{array}{l}\text { Implementing } \\
\text { - Piloting and Rollout advanced project management practices } \\
\text { - Measurements, Risk Management } \\
\text { - Maturing based on the first successes } \\
\text { - Piloting basic project management practices } \\
\text { - Focus on project management work products (basic) } \\
\text { - Implementing "low hanging fruits" and generating short term wins }\end{array}$ \\
\hline $\begin{array}{l}\text { Level } 1 \text { (Organization) } \\
\text { Creating drive for change } \\
\text { and establishing } \\
\text { organizational structures } \\
\text { for systematic project } \\
\text { management }\end{array}$ & $\begin{array}{l}\text { Establishing } \\
\text { - Setting up and developing Project Management Framework } \\
\text { - Establishing Project Management Process Group (or PMO as a driving power) } \\
\text { - Obtaining sponsorship and commitment } \\
\text { - Defining goals } \\
\text { - Assessing the current state } \\
\text { - Creating need for change }\end{array}$ \\
\hline
\end{tabular}

Fig 1. Project Management Process Improvement Model (PM-PIM)

The focus of the model is software-intensive organization and its component-projects. The discussion of the model elements is presented in the article below, taking into account successful and sustaining implementation of project management process improvement.

\subsection{Level 1 - Establishing}

The Establishing level refers to creating the organizational environment for the successful improvement of project management practices. It is about creating drive for change in project management, assessing the current state of project management practices, defining goals based on the organizational business goals and assessment results, obtaining sponsorship and creating a guiding coalition for the project management initiative, collecting the right people on board and working out the first Project Management Framework. It is the responsibility of the organization to achieve all the points discussed in the Establishing level. Before starting the operational project management process improvement work with the projects, the issues discussed in the Establishing level should already be in place.

Creating need for change. Introducing a systematic project management process is usually linked with the change to the current "lived" processes. Before starting the 
improvement work the company must understand the reasons for doing the work. There are different sources, which drive the need for change in project management. These sources can be internal (poor results from past projects, firefighting, recall actions, improvement initiatives, business goals, management requirements) or external (market trends, studies, customer expectations, regulatory and governments requirements) to the organization.

There must be a real sense of urgency in the organization to provide a right set-up for project management improvement initiative. The organization must really want to move, to change the current way of working. Usually the best way to achieve this is to learn by its own experience of the problems in the past. Some examples are the firefighting situation at the end of the project, using too many resources on fixing the problems, huge cost overruns or even putting in danger the vehicle development project end milestone - called Start of Production (SOP).

"Feeling the pain" is the best driving factor for starting with the deep-grounded project management process improvement. On the other side, if the company has not experienced any problems itself, it is rather hard for the employees to understand that there is a need for change. It is then the role of management to convince the teams and also themselves that the change and improvement are needed. Creating the need for change - it is about being proactive - thinking about potential problems before they occur.

Assessing the current state. Assessing the current state of project management is about determining where you are now. The current state of the project management processes should be assessed in order to determine, what is already in place and what needs to be done to close the gaps in the current "lived" project management processes.

While assessing the status of the project management practices some process reference models can be helpful. One of the reference models - Capability Maturity Model Integration (CMMI) - provides a description of the "best practices" for project management [2-3]. The project management in CMMI is divided in some Process Areas, both on the fundamental as well as on the progressive level. The fundamental Project Management Process Areas includes Project Planning (PP), Project Monitoring and Control (PMC), and Supplier Agreement Management (SAM). The progressive project management Process Areas includes Integrated Project Management (IPM), Risk Management (RSKM), Integrated Teaming (IT) and Quantitative Project Management (QPM). These CMMI project management Process Areas cover activities related to project planning, monitoring and control. They provide a lot of guidance on what is important for the systematic project management. The CMMI model enables to assess the current project management practices, identify gaps against the CMMI project management practices and define actions, which need to be implemented in order to improve project management practices.

Another alternative to assess project management is using another model ISO15504 / SPICE [4]. In this model project management plays also a central role. The process group Project Management (MAN3) deals with project management. Some other process groups provide additional details on project management, i.e.: Risk Management (MAN5) or Measurement (MAN6). The usage and importance of the process reference models in the software-intensive automotive industry is well 
visible at the example of the SPICE model. In the year 2005 the new version of the SPICE model was created with the focus on the automotive industry. The result is Automotive SPICE [5]. This model adds on the additional automotive focus to the standard SPICE model. Project management plays here an important role. Most of German automotive OEMs assess project management implementation of its suppliers, using SPICE as a reference model.

Performing an assessment against the reference model results in a list of the organization's strengths and weaknesses in the project management process. At the end of the assessment the clear picture of the project management current state is available and project management process improvement roadmap is established.

Defining Goals. Goals specify where you want to go. Having the picture of the current state, you can define where are the gaps in the project management process and then you can define where you want to go. The important input for definition of the improvement goals is the result from the assessment of the current project management process. In addition, the goals for project management processes should be derived from the organizational business goals and process improvement objectives. Defining goals for project management visualizes, how the project management fits within the overall process improvement initiative, and also within the business organizational context.

Obtaining sponsorship and commitment. For every improvement initiative there is a need for a strong sponsorship from the senior management. Senior management plays a sponsor role and is responsible for linking the project management process improvement activities to the organization's vision and mission.

It is important that a sponsor has a management role at a high enough level in the organization structure. The sponsor has an authority to direct activities, states the objectives and commits the allocation of resources (people, materials, funding) for project management process improvement initiative.

Senior management sponsor should be involved and committed to the project management improvement activities. This involvement and commitment is demonstrated for example by defining organizational policies, presenting the project management improvement effort goals at the employee forum. The sponsor must "walk the talk". It means, even in the technical problem situation the organization will stick to the project management policies. For example, if the policy states that every project is asked to perform risk management workshop, the senior management will force to do so, even if a project manager will try to avoid it by showing that there is no time for risk management. Another sign of the sponsor commitment to project management improvement initiative is showing interest in the work progress, encouraging and participating in the reviews of project management improvement activities.

It is also the job of a sponsor to remove barriers and obstacles that block the project management process improvement effort. The value of a sponsor cannot be underestimated. Strong, committed and proactive sponsorship is the key factor to the success of project management process improvement activities. 
Establishing Project Management Process Group (or PMO as a driving power). The Project Management Process Group (PMPG) is a group of people interested in project management. It is a driving power for successful implementation of the change in project management. This group manages the project management process definition activities. It is typically staffed by the professionals whose primary responsibility is coordinating project management organizational process improvement.

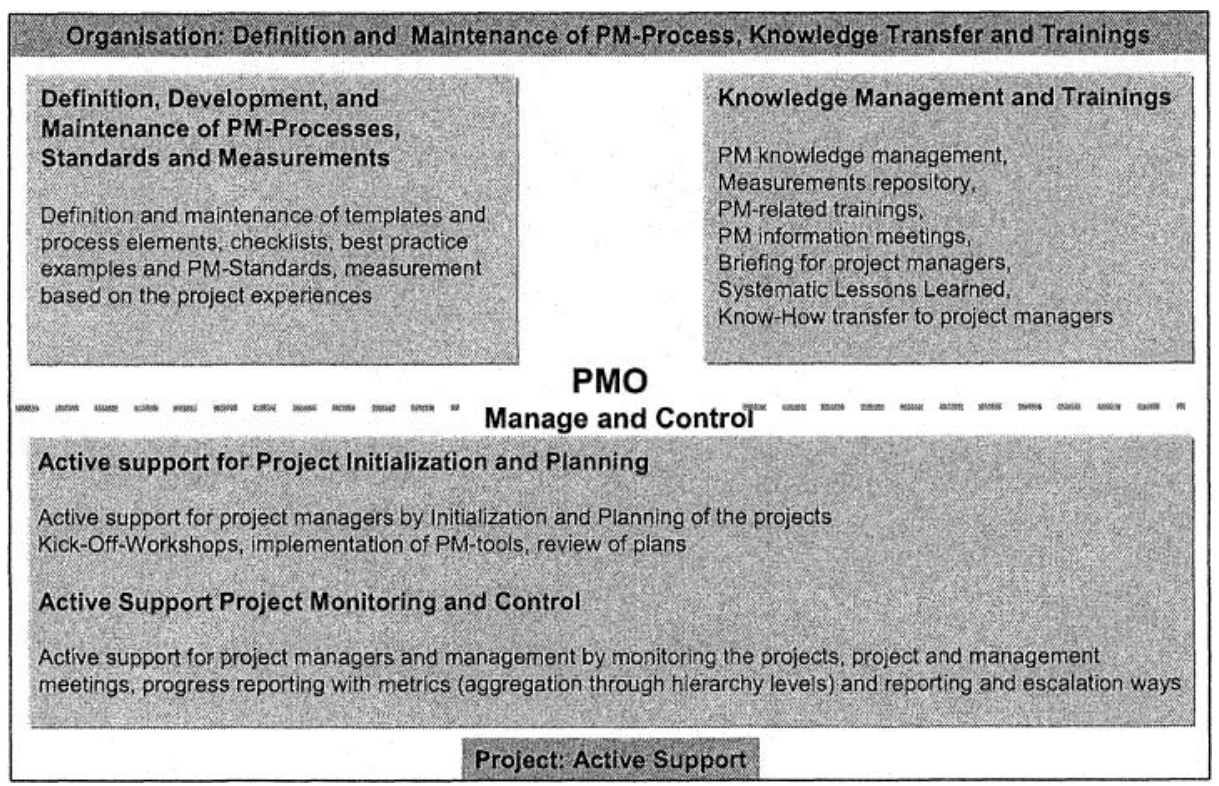

Fig. 2. Role of PMO in the organization

This Project Management Process Group is usually concentrated around Project Management Office (PMO). The practical experiences show that installing the PMO in the organization will facilitate and speed up the project management process improvement. PMO is an organizational unit, which is used to centralize the project management expertise and manage the projects. While introducing a systematic project management, PMO will play an important role, serving the projects with the project management competence, and also supporting by the introduction of the PM methods and tools. The role of the PMO is presented in Figure 2.

PMO provides support by implementing and improving project management in the component-project. Some additional PMO features to be underlined while improving project management processes are:

- Assessing current "lived" PM processes, identifying gaps and defining actions

- Identifying, applying and improving of project management processes

- Using industry-proven PM methods and techniques

- Training-by-doing / coaching / "hands-on" support

- Involving all relevant parties (projects, suppliers, departments and teams) 

projects

Setting up and developing Project Management Framework. There is a need to develop and set up the Project Management Framework. It is about preparing the first definition of the project management process. The findings from assessments are used. PMO members contribute with their various project management experience. Best project management practices and guidelines, taken from the reference models are also beneficial. The project management process description is mapped to the organization structure. The objective is not to provide a perfect, $100 \%$ ready process description. It is more about the first draft of the project management process, which is good enough to start with the first implementation.

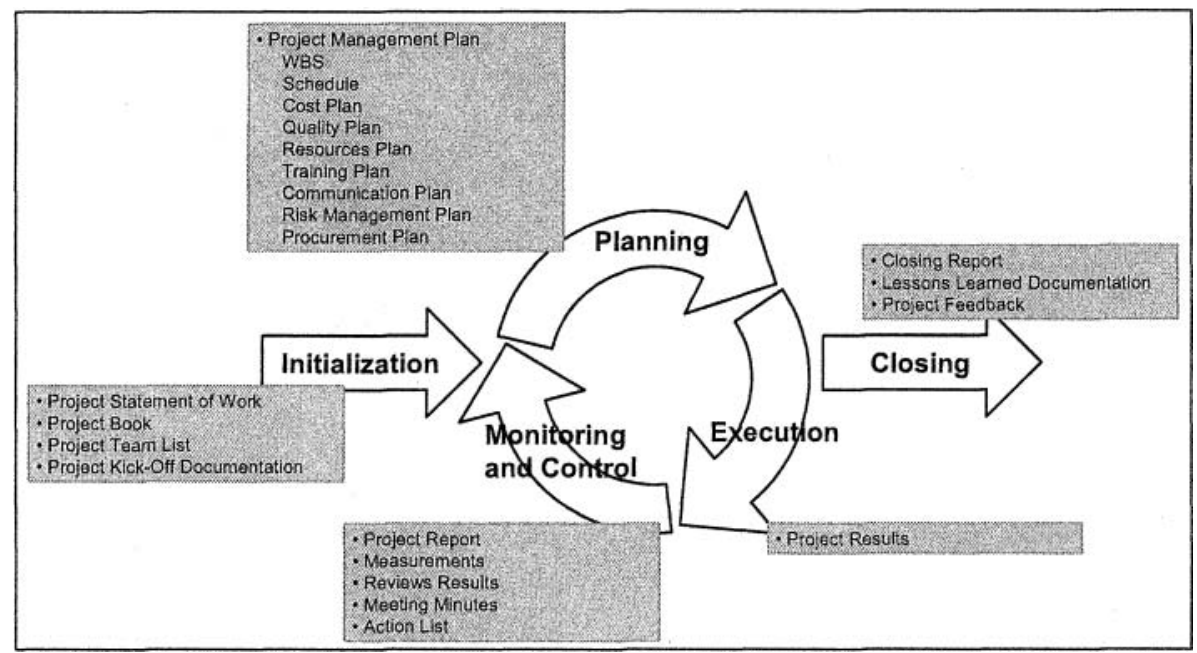

Fig 3. Overview of the project management process with work products

Project Management Framework describes the project management process and includes also the basic set of pre-defined templates describing project management work products (see Figure 3).

In addition, the visualization of the link between project management process and the organization (existing organizational processes, organization departments and teams) is also provided.

\subsection{Level 2 - Implementing}

The Implementing level is about piloting and rollout of the improved project management practices across the projects within the organization. It is done in two phases. At the beginning basic project management practices are introduced, starting with some selected pilot projects. In the next phase more advanced project management practices are implemented. The objective is to reach all projects in the organization. It is the responsibility of the projects, especially project leaders, to implement the improved project management practices. While implementing the practices the project leaders receive active support from Project Management Office. 
Piloting basic project management practices. The first phase of the Implementation level is about implementing the basic project management practices. In some selected pilot projects first elements of project management process are introduced. This first step is to pilot and gain acceptance of the improved project management practices across projects.

At the beginning, it is important to select small improvements with quite a lot of impact on the projects. In order to identify these elements the results of the project management assessment are used. The assessment results make visible, where are the gaps in the project management process and improving which of them can be most beneficial for the projects. It is about picking up the "low hanging fruits - issues with low effort and high positive impact for the projects. They can be quickly implemented in the projects and they bring visible positive improvements in the projects. In consequence, they will generate acceptance for the project management initiative among project leaders. These first "short-term wins" are crucial for the further success of the whole project management improvement initiative. Short-term means here days or weeks, not months.

Project leaders in software-intensive automotive projects are more technical experts than project managers, with a strong orientation on delivering results and less experience in process management. In order to facilitate the project management process improvement, the work should concentrate on working out the project management work products. The work products are the tangible results of the project management process. Concentrating on the work products brings more focus, results in the tangible deliverables and drives the project management work into the right direction. And while working with the work products the people learn how the project management process works.

Some of the project management work products, which are worked out at the beginning of the project management improvement initiative include:

- Statement of Work

- Project Book

- Work Breakdown Structure (WBS)

- Project Management Plan (first draft)

- Project Report (simplified)

- Action List

Introducing these elements brings the first project management benefits into the project life. The role of the Project Book and Project Report are discussed with more details below.

Project Book. The experiences show that introducing the Project Book brings the project management structure in the early phase of the project life. Project Book is the central document for project agreements and starting point for all relevant project information.

The Project Book consists of the following elements:

- Project content (objectives, scope, assumptions \& constraints, milestones)

- Project organization (project chart, infrastructure, meetings, tools)

- Roles and responsibilities

- Processes (selection of the processes relevant for the project) 

projects

The project leader creates or manages the development of a Project Book. The elements documented it the Project Book create the baseline for further work on the project. The component project is usually placed within the organizational structures, including system projects, product lines, competence centers, organization departments and multiple suppliers. Creating and clarifying elements of the Project Book helps to deal with all these relevant parties. One important issue is to describe the project roles and responsibilities. It helps the project leader to reach commitment on the project from project participants.

Project Report. When the project runs, then the Project Report is a valuable project management tool. Project reporting determines where is the project in terms of schedule, budget, functionality and quality. It is about looking at the decisions needed to be taken, problems or foreseen risks. The project leader creates the Project Report. The status of the project is a result of his professional judgment, with consultation with component-project supplier and other project team members. The Project Report is used to report all relevant aspects of the project to the relevant project stakeholders. It can also be used to escalate the issues, which cannot be solved within the project. Project reporting helps to take decision on the future of the project. It is important to integrate the Project Report in the project lifecycle. The Project Report should be prepared in regular time intervals, for example as a part of the project meeting.

Typical content of Project Report includes:

- Overall project status (e.g.: traffic light with reasoning)

- TOP Topics: Highlights, Decisions, Milestones, Defects, Risks, Non-technical Problems, Next Steps

- Project progress measurements (in more advanced status reporting)

The Project Book and Project Report are discussed here in detail, due to the fact, that they have proven the high usability during the work within the component projects. Other project management work products are also inevitable. Implementing the proper project management you should not forget a careful preparation of the project work breakdown structure and project management plan. You cannot control your project without having a proper plan.

Piloting and Rollout advanced project management practices. In the second phase of the Implementation level more advanced project management practices are introduced. It is about further refining a basic project management practices. Measurements are introduced and risk management process is implemented.

Measurements. Measurements provide an added value for monitoring and control of the project progress. They are collected and analyzed as a part of the project status reporting. They are visually presented in the cockpit chart. The project metrics are derived from the project objectives. The experience shows that usually the following set of measurements will fulfill the project management progress monitoring requirements:

- Milestone Trend Analysis

- Effort / Rework

- Activities / Work Packages

- Functionality / Work Products 
- Defects / Problems

- Risks

The measurement process is also introduced. It describes how to define, describe, collect, analyze and report the measurement data. The measurement process provides guidance on how measurement activities should be performed in the project. It provides methods and tools for defining measurement goals, creating operational measurement definitions, and presenting and analyzing the measurement data.

Risk Management. Risk management process describes how to perform project risk management in the structured, organized way. It is about introducing the systematic approach in managing component project risks. It also refers to extending the viewpoint of the technical oriented project leaders. Usually component project leaders understand risk management as the technical analysis of the potential problems in the product. But risk management involves also project or process aspects. Project risks are for example schedule, people resources, budget, interfaces, project stakeholders or politics. Process risks are for example development processes, management processes, standards, policies, quality or communication. Risk management introduces a change in the way of thinking of the project leaders - from the technical product centered to the project, product and process centered. It also introduces another shift in the projects - from the problem solving modus to proactive way of working. Risk Management enables to identify some potential problems before they occur. It is about thinking what can go wrong, and acting against it. Risk management address issues that can endanger the achievement of project objectives (time, scope, budget, quality). Risk management enriches and complements very well with the project management process.

The goal of the rollout phase of the Implementation level is to reach with the improved project management practices all projects within the organization. While implementing the PM-practices, the first experience has been collected. The results and experience achieved by the projects in the Implementing level should be stored and prepared for the further use. It is the role of the organization to make sure that the improved project management will stay and continually improve. This is a topic of Level 3 - Sustaining the project management process improvement.

\subsection{Level 3 - Sustaining}

The Sustaining level is to ensure that the project management is anchored in the organization. It is about improving the project management practice in the organization. It also means managing the organization's projects based on facts - using the measurement data.

Quantitatively managing projects. The measurements are collected in the projects and used to control the projects at the organizational level. The data are aggregated according to prior defined reporting structures. For example, the measurement data can be aggregated within the department or product line, according to the measurement customer needs and objectives. The measurements are used to take decisions not 
only at the component project level, but also at the organizational level. The organization is then managing by facts.

Having the measurement data collected, more advanced analyses of the data are performed. They are performed for the identified, selected important project issues. To perform data analyses more advanced quality management tools are used: e.g.: cause-and-effect diagram, Pareto chart, scatter diagram or control charts.

Continuously improving project management. Continuously improving project management means to collect experiences from the implementation of project management process elements in the projects. It is about providing the organizational structures that support and encourage project management process improvement. At this point the role of Project Management Office is important. The PMO drives the project management knowledge management. As a central organizational structure, PMO facilitates further definition, development and maintenance of project management processes and standards. For more information on the PMO role in Sustaining the project management see also Figure 2.

Project management improvement proposals are continuously collected, analyzed and implemented. At the end of projects Lessons Learned workshops are performed with key project participants. All the relevant project management related information is stored in the project management knowledge repository. This information is analyzed, categorized and prepared for the future use. All future projects can use the experience from the past similar projects.

The organization provides the mature, standardized, organization-wide description of the project management process. All projects can use this universal description. The process description must be tuned to the special needs of different departments, or different project arts. The organization provides Project Management Tailoring Guidelines. The Tailoring Guidelines describe, how the project management will be used in the different organizational settings. It describes, what is required in the project management process implementation, and what can be skipped or modified depending on the environment of the project.

\section{Summary}

Improving project management is about Establishing, Implementing and Sustaining the project management practice in the organization, as summarized in Figure 4.

The article presents an evolutionary approach to project management process improvement, based on the experience with introducing the project management within the software-intensive automotive systems. It systematizes the experience and defines the Project Management Process Improvement Model (PM-PIM). Implementing improvement in project management involves the continuous cooperation between the organization and component projects. The organization creates the required environment, provides support and facilitates the continuous improvement of project management process. The role of the projects is to implement and verify in practice the project management process improvements. 


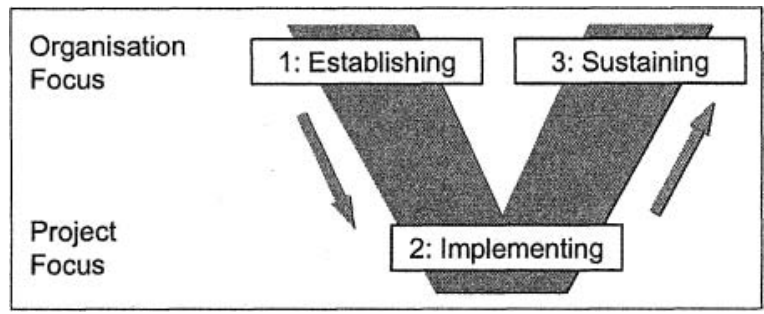

Fig 4. Project Management Process Improvement Model summary

And at the end, it is about successful organizations, happy people and projects being "on time", "in budget" and "in quality".

\section{References}

1. A Guide to the Project Management Body of Knowledge, Third Edition, (PMBOK Guide), Project Management Institute, Newton Square, Pennsylvania, USA, 2004

2. Capability Maturity Model ${ }^{\circledR}$ Integration $\left(\mathrm{CMMI}^{\mathrm{SM}}\right)$, Version 1.1, CMMI Product Team, March 2002 (http://www.sei.cmu.edu/cmmi)

3. CMMI - Guidelines for Process Integration and Product Improvement, Mary Beth Chrissis, Mike Konrad, Sandy Shrum, Addison-Wesley, 2003

4. ISO/IEC 15504 (SPICE) Standard, 2006

5. Automotive SPICE, Process Assessment and Reference Model, Automotive SIG, 2005

6. Project Management, Harold Kerzner, John Wiley \& Sons, 2003

7. The Fast Forward MBA in Project Management, Eric Verzuh, John Wiley \& Sons, 1999

8. Basiswissen, Software-Projektmanagement, Hindel, Hörmann, Müller, Schmied, dpunkt. verlag, 2004 